ZENSUR IN DER WEIMARER REPUBLIK 
Klaus Petersen

\section{ZENSUR IN DER WEIMARER REPUBLIK}

Verlag J. B. Metzler Stuttgart - Weimar 
Für Hanna und Jörn

in dankbarer Erinnerung an all ihre Hilfe

Die Deutsche Bibliothek - CIP-Einheitsaufnahme

\section{Petersen, Klaus:}

Zensur in der Weimarer Republik / Klaus Petersen. - Stuttgart ; Weimar : Metzler, 1995

ISBN 978-3-476-01293-7

ISBN 978-3-476-01293-7

ISBN 978-3-476-03587-5 (eBook)

DOI 10.1007/978-3-476-03587-5

Dieses Werk einschließlich aller seiner Teile ist urheberrechtlich geschützt. Jede Verwertung außerhalb der engen Grenzen des Urheberrechtsgesetzes ist ohne Zustimmung des Verlages unzulässig und strafbar. Das gilt insbesondere für Vervielfältigungen, Übersetzungen,

Mikroverfilmungen und die Einspeicherung und Verarbeitung in elektronischen Systemen.

(C) 1995 Springer-Verlag GmbH Deutschland

Ursprünglich erschienen bei J. B. Metzlersche Verlagsbuchhandlung und Carl Ernst Poeschel Verlag GmbH in Stuttgart 1995 


\section{INHALT}

Vorwort $\ldots \ldots \ldots \ldots \ldots \ldots \ldots \ldots \ldots \ldots$

\section{Einleitung}

I. Innenpolitische, gruppenspezifische und verfassungsrechtliche Voraussetzungen

7

1. Zensur im Rahmen der Ordnungspolitik und des Republikschutzes 9

2. Zensurinteressen sozialer und politischer Gruppen . . . . . . . . . . 17

3. Der Zensurbegriff der Weimarer Verfassung . . . . . . . . . . . . . 31

\section{Obrigkeitliche Kontroll-, Repressiv- und Strafmittel}

41

4. Die kulturelle Gestaltungsmacht des Weimarer Staates . . . . . . . . 42 Schulbuchprüfung und -zulassung; Rundfunkkontrolle

5. Das Lichtspielgesetz vom 12. Mai 1920 . . . . . . . . . . . . . . . . 50

6. Das Gesetz zur Bewahrung der Jugend vor Schund- und Schmutzschriften vom 18. Dezember 1926 . . . . . . . . . . . . 56

7. Strafsanktionen zur Unterdrückung unsittlicher und blasphemischer Äußerungen . . . . . . . . . . . . . . . . 68 Verbreitung unsittlicher Schriften und Abbildungen; Gotteslästerung

8. Die Sanktionierung politisch subversiver Äußerungen . . . . . . . 71 Literarischer Hochverrat; Publizistischer Landesverrat; Aufreizung zu Gewalt und Klassenkampf; Vergehen gegen das Republikschutzgesetz und gegen Verordnungen aus Art. $48 \mathrm{WRV}$ 
Inhalt

9. Die Strafbarkeit der beleidigenden Äußerung . . . . . . . . . . . 77

10. Präventive und repressive Kompetenzen der Polizei . . . . . . . 87

\section{Zensurmaßnahmen und Zensurinitiativen in ihrer Einwirkung auf die Medien}

93

11. Politische Kundgebungen, Plakate, Flugblätter und Broschüren . . 95

12. Die Presse . . . . . . . . . . . . . . . . . . . . 113 Allgemeine Einschränkungen der Pressefreiheit 1918-1933; Völkische und nationalsozialistische Blätter; Linksradikale Parteizeitungen; Die Presse der »liberalen Außenseiter«

13. "Schmutz« und "Schund» . . . . . . . . . . . . . . . . . . . 155

14. Literatur und Kunst . . . . . . . . . . . . . . . . . . 175

15. Theater und Kabarett . . . . . . . . . . . . . . . . . . . . 205

16. Das Lichtspielwesen . . . . . . . . . . . . . . . 245

IV. Ausblick

275

17. Die Weimarer Zensur im Umfeld kultureller und politischer Spannungen . . . . . . . . . . . . . . . . . 277

Quellen und Anmerkungen . . . . . . . . . . . . . . . . . . 299

Literaturverzeichnis . . . . . . . . . . . . . . . . . . . . 332

Personenregister . . . . . . . . . . . . . . . . . . 341 


\section{Vorwort}

Das Material für diese Arbeit wurde auf vier längeren Reisen zwischen 1989 und 1993 aus Akten der folgenden Archive zusammengetragen: Staatsarchiv München; Bayerisches Hauptstaatsarchiv, München; Hauptstaatsarchiv Stuttgart; Nordrhein-Westfälisches Staatsarchiv Münster; Archiv des Deutschen Caritasverbandes, Freiburg i. Br; Hessisches Hauptstaatsarchiv, Wiesbaden; Zentrales Staatsarchiv der DDR (heute Bundesarchiv) Potsdam; Staatsarchiv Potsdam; Bundesarchiv, Koblenz; Bundesarchiv (Militärarchiv), Freiburg, i. Br; Niedersächsisches Hauptstaatsarchiv, Hannover; Landesarchiv Berlin; Evangelisches Zentralarchiv in Berlin; Archiv des Diakonischen Werkes der EKG, Berlin. Ich bedanke mich bei den Mitarbeitern dieser Archive für ihre stets bereitwillige und sachkundige Hilfe. Dankbar bin ich auch dem Deutschen Akademischen Austauschdienst, dem Social Sciences and Humanities Research Council of Canada und der University of British Columbia, die die Reisen und Aufenthalte finanziell unterstützten. Durch die Hilfe der Historischen Kommission zu Berlin und ein Stipendium der Fritz Thyssen-Stiftung in Köln war es mir möglich, das Buch im Winter 1993/94 in Berlin zuende zu schreiben. 